\title{
Key-Factor analysis of elements affecting women's employment in small and medium enterprises (SME) among women living in Tehran
}

\author{
Maryam Zarandi*
}

MA in Business Administration of Allame Tabataee University

\begin{tabular}{l}
\hline A R T I C L E I N F O \\
\hline Article history: \\
Received April 19, 2012 \\
Accepted 12 June 2012 \\
Available online \\
June 142012 \\
\hline Keywords: \\
SME \\
Women's entrepreneurship \\
Beliefs of the society; Employment \\
rate
\end{tabular}

\section{Introduction}

Human tends to have growth and development and the main differences of human being with other creatures are possessing intellectual ability and creativity. In addition, fundamental planning and operation skills as human abilities and talents are what play the effective role in countries' developments (Karatepe \& Olugbade, 2009). The phenomenon of occupation or employment has been taken under consideration since the initial eras of human social life. Hence, women have natural needs for development and activities away from home. In history, women have had the most unfair shares while having the most constructive contributions. In the same complex relationships in history, despite having the best productive and service functions, and more important, their inspiring and motivating roles toward men, women have always had marginal roles in important social positions (Ghasempour, 2002). It can be claimed that one of the most important criteria for evaluating the development rate in a country is how women are regarded and valued in that country (Bruce, 2009).

\footnotetext{
* Corresponding author. Tel: +989192008394

E-mail addresses: m.zarandi2009z@yahoo.com (M. Zarandi)

(c) 2012 Growing Science Ltd. All rights reserved.

doi: $10.5267 /$ j.msl.2012.06.016
}

\begin{abstract}
The recent global developments followed by altered attitudes have improved women's contribution to small and medium enterprises. However, women's employment in Iranian SME cultural environments have resulted in reduced rate of women's employment in developing companies. However, for changing these attitudes the relevant layout should be created anyway. Therefore, the objective of this paper is to enumerate factors affecting women's SME from those women's views. In this regard, we applied Lerner's model which is more comprehensive than the other similar models. The analysis was carried out through distribution of some questionnaires among a statistical population including 384 that economic elements (as an environmental factor), achievement requirement (as an individual factor) and encouragement (as an organizational factors) respectively affect women's employment.
\end{abstract}


Women have significant contributions in SME and therefore supporting their potential participation is essential for economic growth in any country. In all countries, employment and unemployment rates are generally considered as an important economic development index. Furthermore, the matter of women's employment has been specifically considered and emphasized for different reasons in recent years (Kiesner, 1985). The more active and effective women participate in their society, the more developed their country will be. Hence, the rate of women's contribution and participation in their society and particularly in ideological and socio-cultural contexts extremely depends on attitude of the society toward women.

Women have often been considered as the second sex. Of course, depending on women's general socio-cultural conditions in their society, this opinion varies among different countries. We know that traditional attitudes cannot be abolished overnight, but changing attitudes, making technological innovations and using modern ways of thinking can decrease disparities between men and women (Ezzati et al. 2009). Women's motives for employment can be divided into two main categories including mental and economic objectives. Tending to each of these categories depends on socioeconomic class of women's family. In this regard, the most important employment motive for women who belong to leisure class is a mental one while women in middle and lower classes seek for employment because of economic motives (Ezzati et al., 2009). In today's world that women's employment and their directorship in developing organizations are considered as some of progressive methods in economic, social and cultural arenas, they must have the right to fully participate in the social arena in light of their competencies and with regard to transcendental values of the society away from any discriminations, inequities and superstitions. Therefore, our purpose in this paper is to answer the question "what are the key factors affecting women employment in SME?”

\section{Literature review}

While women make up a half of the world's population and work for two-third of the world's working hours, they only own one hundredth of the world's property. Therefore, there are inequities in all societies around the world. In this regard, international organizations have carried out several investigations to study and analyze women's positions in national and international levels, their employment rate, limitations imposed on them, attitudes towards them and their contribution to development as well as policies and strategies made for solving problems concerning women's employment (Parker, 2008). According to statistics, 82\% of employed women work at educational and cultural sections while only less than $5 \%$ of them work at technical, engineering and agricultural service sections. Hence, it is necessary to increase women's share in national economy and fight their unemployment crisis, so that the optimal conditions to develop women's enterprises will be prepared and similarly allow women solve the society's current problems through creating jobs and employment opportunities for themselves and for others as well (Godwyn, 2006). Lots of investigations have been carried out in this matter and some of them are as follows:

In a study about strategic approaches of male and female entrepreneurs toward business effectiveness, Lerner et al. (1997) found that despite some similarities between these two approaches, women pay more attention to quality than men do. Durand (2008) also claimed that achievement evaluation among female entrepreneurs showed that the most important achievement index for women is to reach personal achievement, which is respectively followed by personal goals' fulfillment, traditional economic indices known in entrepreneurship literature such as profit and growth, as well as making a balance between work and life and being effective in society. Some of researchers think that the reason of different meanings of achievement among different groups of female entrepreneurs and also the reason of these differences among male and female entrepreneurs is having or not having children (Justo, 2008). Zhang et al. (2009) found that women rather try to make balance between their economic objectives (including profit \& growth) and noneconomic ones (product quality, personal fulfillment \& helping others), but men have little need to make balance between their personal and occupational goals (for a variety of reasons). In a study carried out about entrepreneurship of Spanish 
female immigrants, González-González et al. (2011) claimed that the most common and typical factors affecting women's employment are their personal and social needs aroused by sexism-based mental pressures that the society has imposed on women and therefore lead them to seek for entrepreneurship, creating jobs and self-employment in order to achieve their own position in capitalist systems (González-González et al., 2011).

\subsection{Attitude of the society toward creating enterprises by women}

In recent years, changes in economic context of women's employment have shown that operation and management rates in enterprises created by women would not be progressed if industrial activities do not reach an optimal growth and advancement (Karp \& Banducci, 2008). Achieving economic, social and cultural balances in a country is possible by eliminating unemployment and increasing employment rate particularly through spreading women's employment and increasing their economic participation in creating developing SME; so in that way, it will improve family subsistence pattern and relationships among family members, children's education and growth as well as development of women themselves (Madanipour, 2006). In today's world, we need empowering women in two ways: employment regulations and enterprises. The first one can result in women's innate empowerment by companies using employment regulations to employ women and the latter results in women acquired empowerment by women creating enterprises or female entrepreneurs (Ezzati et al. 2009). When a society does not well adapt its cultural infrastructures to its socio-cultural requirements, it may face with problems in its way to serious and structural movements. In this regard, we must take action to modify unoriginal attitudes towards women's participation in economy. According to the author of this paper, current attitudes of the society toward women's employment and their way of directorship in SME in different fields such as productive, service and exploitative sections can be enumerated as follows (González-González et al., 2011):

1- Positive and Logical Attitude: In this category, people believe that for achieving development and growth in a country, women's abilities and intelligences should be properly applied in all available areas including in economic aspects of employment. In this regard, it is not only essential to make necessary changes in society or in public attitudes and to contrive for establishment of different enterprises by women, but also it is needed to make women aware of personal and family rights as well as of social and occupational rights concerning their social, cultural, political and economical activities.

2- Historical and Traditional Attitude: In this category, there is a negative attitude toward women's employment and their independence in entrepreneurship in society. People in this category believe that women should be only responsible for housework and for raising children and should not enter political and economic arenas. In this point of view, woman is a housewife and man is the one who is responsible for economic support of the family; and they explain this attitude as they are observing moralities and protecting the security of women in society.

3- Neutral and Conditional Attitudes: In this category, people believe that women's participation in society is reasonable if does not affect their main responsibilities. When there is a disturbance in women responsibilities, this attitude turns to a negative one; otherwise, it remains positive.

\subsection{Position of Women's Employment in Iran}

It can be claimed that women's entry into Iran industry and business occurred about one century after vast participations of Western women in their societies; because technology introduction to Iran lengthened until that time. It should be noted that men constantly remain in business from when they enter into business until their retirement, and life changes do not disturb this continuous participation; while women have discontinuous and interrupted participation where its pattern changes by life conditions such as marital status, number of children, etc. In addition, acceptance of inequalities between men and women in their physical and intellectual abilities has caused limitation of women's 
employment in lots of occupations. Women's social knowledge and their role in economic activities are growing. In December 2006, women economic community has been officially established under the title "Business Women Council" in Tehran Chamber of Commerce aimed at developing women's position in international business activities, information exchange and bilateral cooperation between businesswomen of Islamic countries. According to international organizations and World Economic Forum reports, Iranian women's participation rate as labor force was $42 \%$ in 2008 . Now, Iranian women need some patterns to help them find the proper ways of employment in society. To achieve such patterns, dominant culture of the society and real position of women in their family must be taken into consideration. Based on the last statistics reported by Statistical Center of Iran in 2006, $87.7 \%$ of Iranian employed women are highly educated and $27.3 \%$ of them are not educated. In addition, $36.6 \%$ of employed women are graduated from universities and $12.9 \%$ of employed men are highly educated (Mirghafouri, 2009; p.2).

\subsection{Theoretical Paradigm of the Research}

Barriers against women's employment in enterprises are unfair attitudes and beliefs of some people. There are different elements in a society such as specific economic, social, legal and cultural factors that restrict the development of women's participation in economic activities. Studies showed that the factors affecting women's participation in economic activities have been considered in three areas: individual, organizational and environmental areas. According to Lerner et al. (2000), factors positively affecting women's entrepreneurship are fully explained. Regarding existing attitudes towards women's employment and barriers or problems against it, as well as concerning women's behavioral approach toward factors, which are very similar to the factors affecting their employment in SME. The present study investigates factors affecting women's employment in SMEs according to Lerner's model in which individual experiences and environmental factors affecting development of women's employment has been taken into consideration. Actually, the purpose of this study is to investigate factors affecting women's employment in SMEs located in the city of Tehran. These factors are as follows:

$\checkmark$ Individual factors: These factors are studied based on three characteristics: personality, motivation and goals. The type of women's personality is one of the important factors affecting their employment; in addition, their motivation range and their goals, which are stemming from personality affect their employment (Marian, 2011).

$\checkmark$ Organizational factors: Effect of organizational factors on women's employment is more obvious due to women's less participation in economic enterprises and particularly in creating managerial jobs. Some studies showed that women generally create an emotional space in their work environment. This approach causes employees feel intimacy in their work environment while being serious about their jobs (Peeters \& Ateljevic, 2008). Women treat their employees in a maternal or sisterly manner. This behavior acts as an intermediary, which strengthens intra-organizational relationships. These factors include empowering women in SMEs, supporting women's entrepreneurship organizations, encouraging women's innovations and organizational limitations.

$\checkmark$ Environmental factors: These factors are studied in 4 categories:

- Economic factors: Financial independence and type of women's employment are considered as economic factors. Some of the important motivating factors affecting women's employment include achieving independent revenue, reaching a future of provision and applying an economic position in the society (Bige Askun, 2011; p.665).

- Social factors: This category is studied by dividing into two parts: contribution pattern of successful female entrepreneurs in the society and disparities of women's role within the family and the society. Family limitations against women's employment and their economic activities are generally imposed by their close family members or their husband. In addition, by raising children particularly when they are in early ages and having 
occupational matters, women face with serious problems. Female entrepreneurs often solve and decrease family problems with manners such as being tolerate, talking with their family, creating a team with their husband and showing their abilities by their career achievements (Heilman \& Chen, 2003).

- Cultural factors: These factors include social norms, regulations, traditions, customs and attitudes toward women's employment and entrepreneurship. Factors that are appeared as barriers against women's employment cannot be defeated only by personal efforts and it is required some value-adding modifications and changes in environment. In other words, culture-building is essential to remove these factors. Having negative attitude toward social roles of women, specifying a limited definition for women and limit them to do activities such as housework and raising children are basic reasons resulted in conflictions, oppositions and barriers against women's social presence.

- Political factors: These factors include government laws regarding women and establishing SMEs (Brush \& Hisrich, 2000).

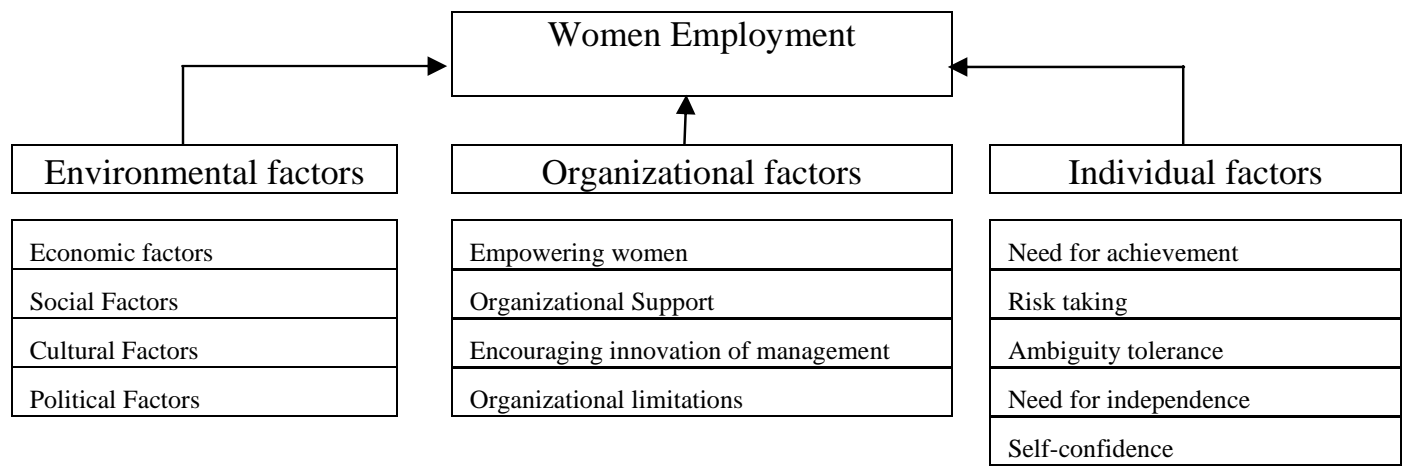

Fig. 1. Based on Lerner, Hisrich \& Brush Model (2000)

\section{Research Methodology}

This paper is an applied research in which we used documentary and filed method of data collection. Also, library research method was used for the theoretical fundamentals; also, the data collection was performed by questionnaires. By formula of sample volume determination, the size of statistical population was decided to be 384 people who were randomly selected among women living in the city of Tehran. Validity of the questionnaire was evaluated by comments of some professors, academic experts working at entrepreneurship areas and highly educated managers of active SMEs in productive and service industries. According to the suggestions, our questionnaire was edited and revised. Reliability of the questionnaire was evaluated by SPSS software and its Cronbach's coefficient alpha was 0.89 (Table 1).

\section{Table 1}

Cronbach’s Coefficient Alpha for Measuring the Questionnaire’s Reliability

\begin{tabular}{ccc}
\hline Index & Cronbach's Coefficient Alpha & Number of Items \\
\hline Questionnaire & 0.89 & 24 \\
\hline
\end{tabular}

\subsection{Data Analysis}

Statistical information and data of this research was collected from 384 women living in Tehran of which $69.7 \%$ were employed. In our statistical population $8.3 \%$ had high school diploma, 36.6\% had associates degree, $40 \%$ had bachelors' degree, $11.7 \%$ had master's degree and $3.3 \%$ had $\mathrm{PhD}$. The age spectrums of the sample population include 25 to 35 years (26.7\%), 35 to 45 years (38.3\%), 45 to 55 years (25\%) and over 55 years (10\%). Results and analyses of the hypothesis testing are outlined in the following table: 
Table 2

Summary of Hypotheses Testing of the Research (Critical Value $=1.96$

\begin{tabular}{cccccr}
\hline Hypothes & Dependent Variable & Independent Variable & Test Statistic & Sig & Test Result \\
\hline First & Economic Factors & & 13.035 & 0.000 & Confirmec \\
Second & Social Factors & & 2.373 & 0.014 & Confirmed \\
Third & Cultural Factors & Women's & 2.001 & 0.001 & Confirmed \\
\hline Forth & Political Factors & Employment in SME & 0.151 & 0.003 & Confirmed \\
Fifth & Risk Taking & & 8.015 & 0.515 & Rejected \\
Sixth & Need for Achievement & & 3.114 & 0.000 & Confirmed \\
Seventh & Ambiguity Tolerance & & 7.035 & 0.000 & Confirmed \\
Eighth & Need for Independence & & 2.731 & 0.000 & Confirmed \\
Ninth & Self-Confidence & & 2.499 & 0.000 & Confirmed \\
Tenth & Empowerment & 3.014 & 0.000 & Confirmed \\
Eleventh & Organizational Support & & 3.24 & 0.000 & Confirmed \\
Twelfth & Encouragement to Innovation & & -6.888 & 1.205 & Rejected \\
Thirteenth & Organizational Limitations & & & &
\end{tabular}

As it is shown in Table 2, result of the hypotheses testing performed by regression analysis was significant in level of 0.05 . In other words, null hypothesis was rejected and the hypotheses were confirmed by $95 \%$ certainty or it can be claimed that the null hypothesis was rejected by $95 \%$ certainty. After hypothesis testing, prioritizing of factors affecting women's employment in SMEs was performed by Friedman test as follows:

Table 3

Results of the Friedman Test

\begin{tabular}{ccccc}
\hline Factor & Economic Factors & Need for Achievement & Need for Independence & $\begin{array}{c}\text { Encouragement to } \\
\text { Innovation }\end{array}$ \\
\hline Mean & 41.3 & 21.6 & 15.06 & 6.77 \\
\hline Factor & Political Factors & Social Factors & Cultural Factors & Ambiguity Tolerance \\
\hline Mean & 6.77 & 5.78 & 4.14 & 3.00 \\
\hline Factor & Self-Confidence & Empowerment & Organizational Support & \\
\hline Mean & 2.88 & 2.63 & 1.96 & \\
\hline
\end{tabular}

\section{Discussion and Conclusion}

Today, all specialists and policy makers come to an agreement on the fact that the most important economic challenge in Iran fourth socio-economic development plan is employment and unemployment discussion. Here, the important point is how to deal with this phenomenon and how to determine and apply the dealing strategies in order to get our country's economic capacities active. Meanwhile, it is important to take advantage of women's capacities (which are one half of Iran population) in establishment, management and employment at SMEs. After different considerations in this study, we concluded that among the above mentioned factors, environmental factors, individual factors and finally organizational factors respectively affecting women's employment in SMEs. Economic factors of the society which are subcategories of environmental factors, mostly affect women's employment in such enterprises because economic structure of the society and the enterprises that seek for women's employment have the most effects on this matter. This finding is compatible with that of studies carried out by Zhang et al. (2009), Langowits et al. (2007), Pedersen (2005) and Godwyn (2009). These researchers also concluded that economic issues of the society affect women's employment and entrepreneurship in a way that if economic conditions of a country cannot cover women's employment in society, about $75 \%$ of resources will be spent for women's job abolishment and this is not out of mind. Regarding the attitude of the present research statistical population, we concluded that risk taking rate does not affect creating SMEs but requirement of independence and self-confidence do affect women's employment in such enterprises. This conclusion confirms results of the research performed by Durand (2008). In a long-term study about women's employment and entrepreneurship, Durand has concluded that risk raking rate have no relation with women's tendency to create SMEs, but their desire for independence and self- 
confidence greatly affect their entrepreneurship. In addition, for organizational factors, organizational limitations have had negative effects, in that the more are the organizational limitations, the less are women's employments in the organization. This conclusion is compatible with results of the research performed by Henry (2003). Factors of encouraging the organization greatly affect women's employment, but organizational support has little effect on it. Finally, regarding the confirmed and rejected hypotheses, this study should make some suggestions to strengthen the positive factors affecting women's employment and also to lessen the negative effects of the other factors.

\section{Suggestions}

Since women provide a considerable labor force of the society, their entrepreneurial performance help economic development of the society in issues including growth of production or sales services, capital increase, employees' welfare, competitiveness and exports in not so heavy scale which is suitable for SME's main approaches. Now, our suggestion is to mention this fact that a society willing to a comprehensive development should provide the environment for growth and talent actualization for all of its members including employed women. Total results of this study shows that in order to develop women's economic activities and encourage them to accept employment in SMEs, we have to inform all members of the society to believe women's abilities.

In this research, effect of cultural factors on women's employment was also taken into consideration. The fact that we must change social norms, regulations, traditions, customs and social attitudes toward women's employment in SMEs, is a time-consuming but effective process. Therefore, we suggest different organizations such as public institutions (including National Youth Organization) or religious institutions (including religious authorities 'offices) and etc. to accept and justify social employment norms to ensure lack of decreasing effectiveness on women's matrimonial responsibilities and on their Islamic veil in other hand. Political factors are the other elements affecting women's employment in SMEs. According to the results of Freidman test, while observing Islamic regulations, women recently have had considerable achievements in Asian and worldwide sports as well as in obtaining ministry and chancellery chairs. This fact can be considered as a proper pattern for facilitating legislation toward women's employment in SMEs. It should be noted that the role of government and parliament in representing and enacting such laws should be seriously considered. According to the results of this research, technological factors had little effects on women's employment, hence a study on towns and suburbs of the city of Tehran in which technology development rate is slow, is recommended as an applied research. Regarding these results, it should be approved that lack of modern technologies cannot be a reasonable cause for women's unemployment living in suburbs of Tehran (with regard to the development of Knowledge Based Organizations in these regions). Based on these results, two factors including requirement of independence and self-confidence among individual factors affecting women's employment in SMEs can be taken into consideration. In this study, we found that changes in women's individual roles in the society are rapidly developing. Today, accepting social roles and employment which are physically and emotionally proper for them, women have been freed of dependence to their father and husband; based on statistics, this rate is increasingly growing. In this regard, our recommendations are facilitating women's participations in different training courses offered by entrepreneurship centers in universities and in organizations such as Municipalities of Tehran and of other cities of Iran; training new skills such as how to increase creativity and establishing SMEs; improving entrepreneurial morale and not merely being employee centric; participating in sport activities; establishing charity institutes and etc. These activities can increase women's independence and selfconfidence. And finally, the last finding of the this research is that encouraging women's innovation and creativity by managers from different organizational levels may be one of the organizational factors clearly affecting women's employment in SMEs. Hence, findings of this research can be considered as fundamental recommendations that have been used to reach its objectives. 


\section{References}

Askun, B., \& Yıldırım, N. (2011). Insights On Entrepreneurship Education In Public Universities In Turkey: Creating Entrepreneurs Or Not? Procedia - Social and Behavioral Sciences, 24, 663-666.

Durand, M. (2008). An Exploration of the Impact of Socialisation on the Decision of a Female to Become an Entrepreneur" International Journal of Entrepreneurship and Innovation, 5(3), 159-165.

Ezzati, M. Seyed Naghavi, M.A. (2009). Entrepreneurship Basics. Labor and Social Security Institute.

Ghasempour, S. (2002). Review of Educated Women's Employment Conditions. Thesis for postgraduate program of studies; Rahpouyan Vesal Cultural Organization, Shiraz.

González-González, J.M., Bretones, F.D., Zarco, V., \& Rodríguez, A. (2011). Women, immigration and entrepreneurship in Spain: A confluence of debates in the face of a complex reality. Women's Studies International Forum, 34(5), 360-370.

Godwyn, M. (2009). This Place Makes me Proud to be a Woman: Theoretical explanations for success in entrepreneurship education for low-income women. Research in Social Stratification and Mobility, 27, 5064.

Heilman, M.E., Chen, J.J. (2003). Entrepreneurship as a solution: the allure of self-employment for women and minorities. Human Resource Management Review, 13(2), 347-364

Henry, C., Hill, F \& Leitch, C. (2003). Entrepreneurship education and training: Can entrepreneurship be taught (part 1). Education and Training, 47(2), 98-111.

Jones, M.V., Coviello, N., \& Tang, Y.K. (2011).International Entrepreneurship research (1989-2009): A domain ontology and thematic analysis. Journal of Business Venturing, 26(6), 632-659.

Justo, R., Cruz, C., De Castro, J., Coduras, A. (2006). Entrepreneurs' Performance of success: Examining differences across gender and family status, IE working paper N. WP06-07, instituto de empressa business school, 20.

Karp, J.A., \& Banducci, S.A. (2008). When politics is not just a man's game: Women's representation and political engagement. Electoral Studies, 27(1), 105-115.

Kato, K., \& Pedersen, N. L. (2005). Personality and coping: A study of twins reared apart and twins reared together. Behavior Genetics, 35, 147-158.

Karatepe, O.M., \& Olugbade, O. A. (2009).The effects of job and personal resources on hotel employees' work engagement. International Journal of Hospitality Management, 28(4), 504-512.

Kiesner, W. F. (1985). Small Business Course Content, Training and Other Critical Factors in the Success of Small Business Training Courses. Montreal, Canada, Paper Presented to the 30th Annual World Conference of the International Council for Small Business, No. June.

Langowitz, N., \& Minniti, M. (2007). The entrepreneurial propensity of women. Entrepreneurship Theory and Practice, 31, 341-364.

Latest News (2010). Job \& Employment News \& Reports. See more: http://www.jobportal.ir

Lerner, M., Brush, C., \& Hisrich, R. (1997). Israeli women entrepreneurs: An examination of factors affecting performance. Journal of Business Venturing, 12(4), 315-339

Mafi, P. (2008). Employment and Entrepreneurship Pathology in Iranian Society. See more: http://www.jobportal.ir

Madanipour, N. (2006). A Review of Women’s Employment”, Payam-e-Zan Moonthly Magazine, 173.

Mirghafouri, S. H., \& Sayadi Touranlou, H. (2009). Clarification and analysis of effective barriers against women's entrepreneurship. Transformation Management Journal, 1(2).

Peeters, L.W.P., \& Ateljevic, I. (2008). Women Empowerment Entrepreneurship Nexus in Tourism: Processes of Social Innovation, Tourism and Entrepreneurship, 76-80.

Parker, S.C. (2008). Entrepreneurship among married couples in the United States: A simultaneous profit approach. School of Economics, Finance and Business, 23-26.

Roomi, M.A., \& Harrison, P. (2008). Training needs for women-owned SMEs in England. Education + Training, 50(8/9), 687-696.

Sa'ar, A., \& Gooldin, S. (2009).Intense engagement: Young women in Israel forging feminist subjectivities. Women's Studies International Forum, 32(3), 179-188.

Zhang, Z., Zyphur, M.J., Narayanan, J., Arvey, R.D., Chaturvedi, S., Avolio, B.J., Lichtenstein, P., \& Larsson, G. (2009). The genetic basis of entrepreneurship: Effects of gender and personality. Organizational Behavior and Human Decision Processes, 110(2), 93-107. 